\title{
Silicon Nanotubes as Potential Therapeutic Platforms
}

\author{
Nguyen T. Le, Yuan Tian, Roberto Gonzalez-Rodriguez and Jeffery L. Coffer* \\ Department of Chemistry and Biochemistry, Texas Christian University, Fort Worth, TX 76129, USA; \\ nguyen.t.le@tcu.edu (N.T.L.); Yuan.tian@tcu.edu (Y.T.); R.gonzalezrodriguez@tcu.edu (R.G.-R.) \\ * Correspondence: j.coffer@tcu.edu; Tel.: +01-817-257-6223
}

Received: 27 September 2019; Accepted: 28 October 2019; Published: 1 November 2019

\begin{abstract}
Silicon nanotubes (SiNTs) with unique well-defined structural morphologies have been successfully fabricated and recognized as a novel architecture in the nanoscale Si family. While the typical dendritic microstructure of mesoporous silicon prepared anodically has been exploited previously for therapeutics and biosensing, our status of utilizing SiNTs in this regard is still in its infancy. In this review, we focus on the fundamental properties of such nanotubes relevant to therapeutic applications, beginning with a description of our ability to sensitively tune the structure of a given SiNT through synthetic control and the associated detailed in vitro dissolution behavior (reflecting biodegradability). Emphasis is also placed here on the range of functional moieties available to attach to the surface of SiNTs through a summary of current studies involving surface functionalization and strategies that facilitate conjugation with molecules of interest for multiple purposes, including cell labeling, nucleotide attachment, and scaffolding of therapeutic metallic nanoparticles. Experiments addressing our ability to load the interior of a given nanotube with species capable of providing magnetic field-assisted drug delivery are also briefly described. Given the range of diverse properties demonstrated to date, we believe the future to be quite promising for employing SiNTs as therapeutic platforms.
\end{abstract}

Keywords: silicon nanotubes; surface chemistry; drug delivery

\section{Introduction}

For some time, porous silicon ( $\mathrm{pSi}$ ) has attracted great attention in applications relevant to diagnosis and therapy, owing in part to its biocompatibility and biodegradability in aqueous physiologicallyrelevant environments [1-4]. Such a response in vitro/in vivo of $\mathrm{pSi}$ is sensitively dictated by porous morphology, associated Si domain dimension and surface chemistry [4,5]. While demonstrating utility in applications as diverse as bioimaging [6], drug delivery [7], and nucleotide sensing [8], pSi in a mesoporous form also exhibits some detrimental properties, namely intricate dendritric morphologies, and requires corrosive reagents in its preparation and expensive starting material (wafer grade $\mathrm{Si}$ ). Among alternative nanostructured forms that minimize such undesirable properties, one-dimensional nanotube constructs with unique well-defined hollow interior spaces and curved side walls have captured significant interest in the investigation of new properties and potential merit in diverse fields $[9,10]$. To successfully prepare such a morphology, a $\mathrm{ZnO}$ sacrificial template method was successfully developed, which yields a broad library of silicon nanotubes (SiNTs) with controllable structural parameters (inner diameter, shell thickness, length and surface morphology) [11]; under selected fabrication conditions, porous sidewalls can also be incorporated as a part of the nanostructure morphology (pSiNTs).

While SiNTs have been actively evaluated in several applications, including Li ion batteries [12] and photovoltaics [13,14], this review focuses on biomaterial aspects of SiNTs. To be qualified as a relevant candidate in biomedical applications (e.g., drug delivery and biosensing), an understanding of stability and degradation rate of a selected matrix is required [15]. In this discussion, dissolution 
behavior of a large family of SiNTs at physiological temperature is emphasized, thereby elucidating biodegradability properties of a given nanotube type. In terms of therapeutic platforms, there are ample opportunities to exploit this tubular nanostructure for multiple purposes. While the inner void spaces of SiNTs are favorable for housing therapeutic species, the tunable surface chemistry of SiNTs is exploited to facilitate coupling reactions with various targeting molecules or therapeutic moieties [10]. Specifically, owing to high surface area and synthetic route, SiNTs present an oxide-rich interface; therefore, such a native oxide of SiNTs allows facile surface functionalization via formation of a stable siloxane Si-O-Si bond with a molecule containing silanol groups [16]. A well-established approach to extend functionality of the material is to use a linker with a free moiety on the distal end that can interact with molecules in the surroundings [17]. To probe the utility of SiNTs as a possible therapeutic matrix, our group has explored multiple strategies using aminosilane species, particularly 3-aminopropyltriethoxysilane (APTES), to allow conjugation to several molecules of interest, thereby: (1) Altering dispersion properties of SiNTs in aqueous environments; (2) enabling fluorescent labeling for detecting the nanotube in biological environments; and (3) facilitating complex formation with polynucleotides (e.g., plasmid DNA or siRNA) for potential gene therapy.

Thus, in this article we focus on several fundamental aspects of SiNTs relative to their possible utility as a therapeutic platform: (1) Convenient synthetic protocols; (2) temporal degradation in biologically-relevant media; and (3) surface modification strategies. As we will see shortly, the latter category has implications not only with regard to imaging and delivery, but also in our ability to create more sophisticated metal-semiconductor nanostructures, also of therapeutic value. Finally, we also demonstrate proof of concept in loading the large interior of the nanotube, utilizing superparamagnetic nanoparticles.

\section{Fabrication of Silicon Nanotubes}

Silicon nanotubes with a well-defined structure are readily fabricated via a sacrificial $\mathrm{ZnO}$ nanowires (NWs) template method (Figure 1) [11]. In this approach, $\mathrm{ZnO}$ NWs are grown on a substrate (e.g., Si wafer or fluorine-doped tin oxide (FTO) glass) pre-deposited with ZnO nanocrystals and are subsequently coated with a Si layer by performing chemical vapor deposition (CVD), in which silane $\left(\mathrm{SiH}_{4}\right)$ diluted in He gas $(0.5 \%)$ serves as a precursor. Hollow SiNTs are achieved via a gas-phase etching process, which involves decomposition of $\mathrm{NH}_{4} \mathrm{Cl}$ into $\mathrm{NH}_{3}$ and $\mathrm{HCl}$ at $450{ }^{\circ} \mathrm{C}$ in $\mathrm{He}$ to remove the $\mathrm{ZnO} \mathrm{NW}$ core. By controlling $\mathrm{ZnO}$ growth conditions (i.e., concentrations of $\mathrm{ZnO}$ precursors $\left(\mathrm{Zn}\left(\mathrm{NO}_{3}\right)_{2}\right.$ and hexamethylenetetramine (HMTA) and growth time), the subsequent average inner diameter and length of SiNTs can be manipulated from 30 to $200 \mathrm{~nm}$ and $500 \mathrm{~nm}$ to $10 \mu \mathrm{m}$, respectively (Figure 2). Interestingly, via control of the CVD process, not only can the thickness of the Si shell can be sensitively adjusted (10-100 nm thickness), but a distinct surface morphology of SiNTs is also achieved. Specifically, when the Si sidewall thickness is limited to $10-12 \mathrm{~nm}$, a unique porous morphology is obtained as a result of $\mathrm{Si}$ island formation via an Ostwald coalescence process. The porosity of such walls can be readily demonstrated in a simple chemical diffusion experiment involving infiltration of small luminescent molecules (e.g., the luminescent dye tris(bipyridyl) ruthenium(II), $\mathrm{Ru}(\mathrm{bpy})_{3}{ }^{2+}$ ) (Figure 2g) [11]. As the shell grows thicker, porous features disappear and the outer surface becomes smoother (Figure 2h). An additional annealing step at $600{ }^{\circ} \mathrm{C}$ in $\mathrm{He}$ can be performed to enhance the crystallinity of SiNTs.

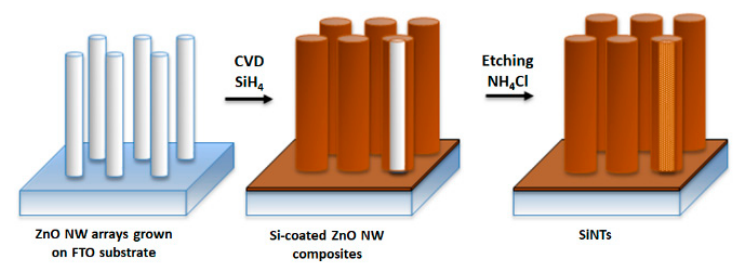

Figure 1. Fabrication scheme of silicon nanotubes (SiNTs)—ZnO nanowires (NWs) sacrificial template method. 


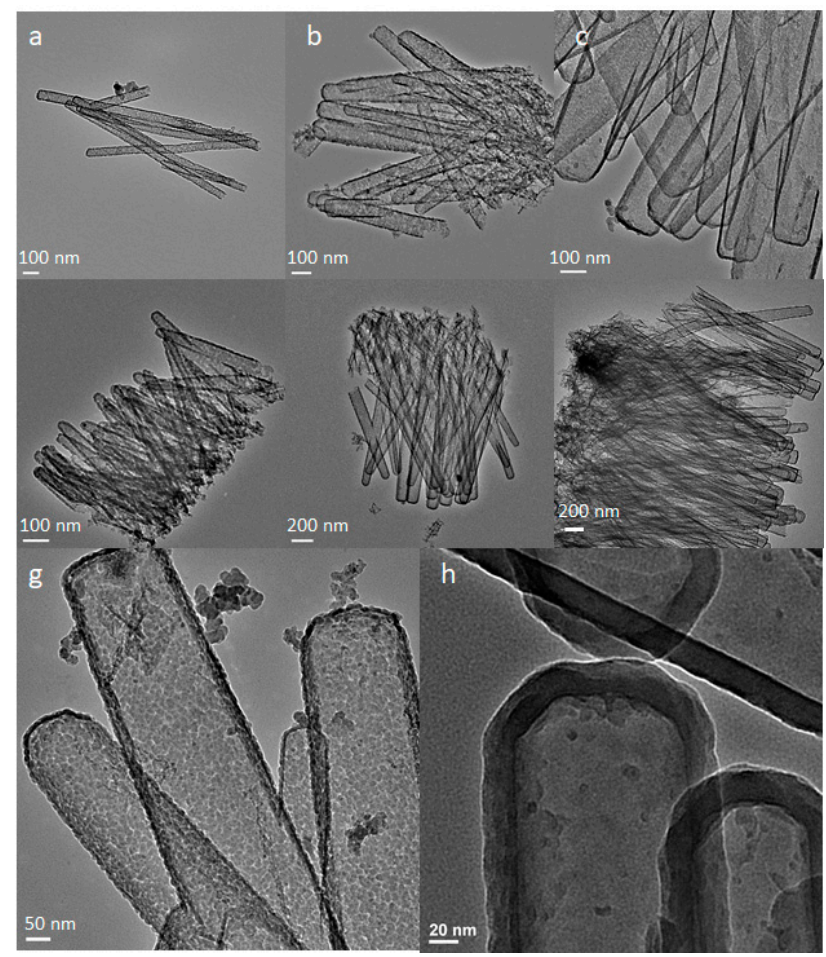

Figure 2. Structural and surface morphology of SiNTs. Tunable inner diameter: (a) $50 \mathrm{~nm}$, (b) $100 \mathrm{~nm}$, (c) 150-200 nm. Tunable length: (d) $500 \mathrm{~nm}$, (e) 1.5-2.0 $\mu \mathrm{m}$, (f) 2.5-3.0 $\mu \mathrm{m}$. Surface morphology: (g) 10-12 nm highly porous side wall, (h) $20 \mathrm{~nm}$ non-porous Si shell.

\section{Dissolution Properties of Silicon Nanotubes}

Biological applications of SiNTs require careful evaluation of the biodegradation behavior of the materials in a simulated physiological environment. Based on a molybdate-based spectrophotometric method, dissolution kinetics of a variety of SiNTs have been examined [11,18,19]. In phosphate-buffered saline (PBS) at physiological temperature $\left(37^{\circ} \mathrm{C}\right)$, dissolution kinetics of SiNTs is strongly dependent on shell thickness and crystallinity [11,19]. Presumably due to high surface area, SiNTs with thinner walls expose more reactive surface species, thereby dissolving faster than relatively thicker ones. For unannealed SiNTs, while some variation in sample-dependent dissolution kinetics exist for the $10 \mathrm{~nm}$ wall porous SiNTs (70-100\% dissolution after 2 days), resorption of SiNTs with a thicker wall is significantly slower (38 nm: 15\%; $80 \mathrm{~nm}$ : 5\%) (Figure 3a) [11,19]. Interestingly, dissolution behavior of porous $\mathrm{SiNTs}$ is similar to bioactive anodized mesoporous $\mathrm{Si}$, where the degradation occurs in the form of soluble $\mathrm{Si}\left(\mathrm{OH}_{4}\right.$ (and is eliminated from the body via the kidneys in a non-toxic manner), thereby implying favorable biodegradability of this type of SiNT [1]. In contrast, within the same time frame, dissolution of the annealed SiNTs drops to less than 5\% for all shell thickness; nevertheless, dissolution kinetics still follows the same trend observed in unannealed samples with thin, porous SiNTs resorbing faster than the $38 \mathrm{~nm}$ wall, followed by $80 \mathrm{~nm}$ walled SiNTs (Figure $3 \mathrm{~b}$ ).

Since dissolution behavior of SiNTs depends on the media utilized in a given experiment [11], in another experiment the complete cell culture medium was chosen since it more closely mimics biological conditions [18]. In addition, to examine the impact of the degraded byproducts of SiNTs to cell viability, human embryonic kidney (HEK) 293 cells grown in the culture medium were exposed to SiNTs. Surprisingly, while a significant amount of SiNTs with a $\sim 50 \mathrm{~nm}$ wall remained visible after a 2-day incubation in PBS, SiNTs resorbed significantly faster in the complete medium (no cells), since almost all the nanotubes dissolved within the same time interval [18]. However, due to the complex nature of the growth medium, it is still unclear which compositions facilitate rapid dissolution of SiNTs. When SiNTs were incubated with HEK 293 cells, not only the dissolution of SiNTs was 
relatively fast, as indicated above, noticeably, cells were still healthy and proliferated normally, hence confirming biocompatibility of this material [18].
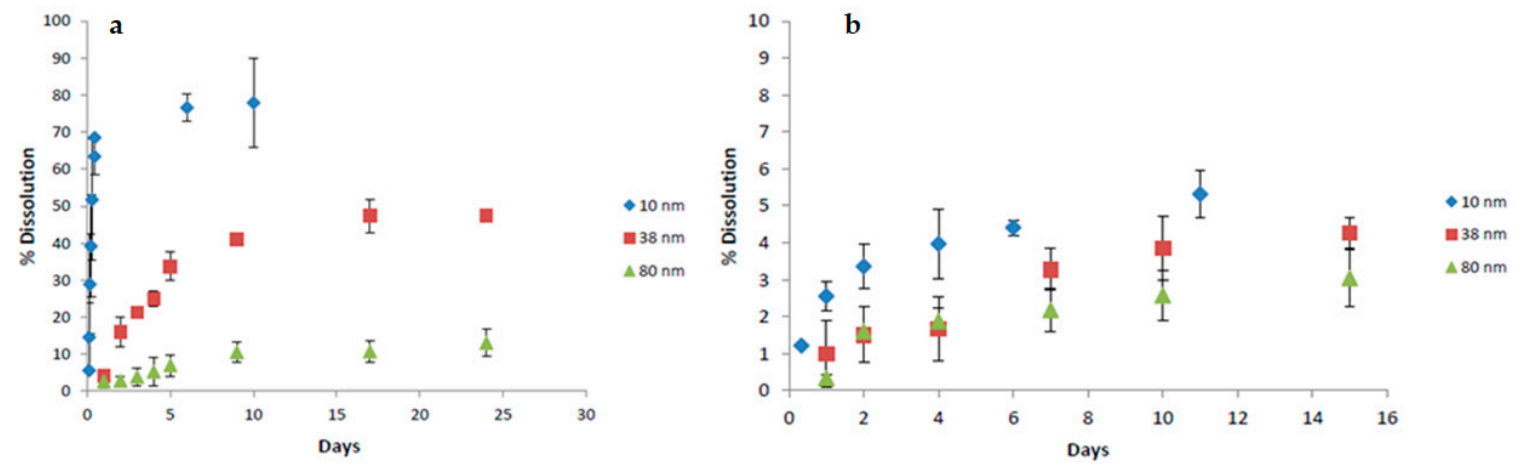

Figure 3. Percent dissolution of unannealed SiNTs (a) and annealed SiNTs (b) with wall thickness of $10 \mathrm{~nm}, 38 \mathrm{~nm}$, and $80 \mathrm{~nm}$ in phosphate-buffered saline (PBS) at $37^{\circ} \mathrm{C}$ (adapted from [19] with permission).

During the course of dissolution studies using the cell culture medium, morphological changes of SiNTs in the presence of cells were also monitored. Optical imaging showed that the color of SiNT arrays transformed from opaque black (in the initial $50 \mathrm{~nm}$ wall thickness) to transparent brown as the Si shell gradually became thinner, reaching a value of $12.63 \pm 2.83 \mathrm{~nm}$ after 3 days, thereby suggesting approximately $75 \%$ of SiNTs dissolved (Figure 4). However, since multiple components of the complete medium interfere with the molybdate assay, specific quantification of the dissolution rate of SiNTs in the growth medium cannot be determined via this route.

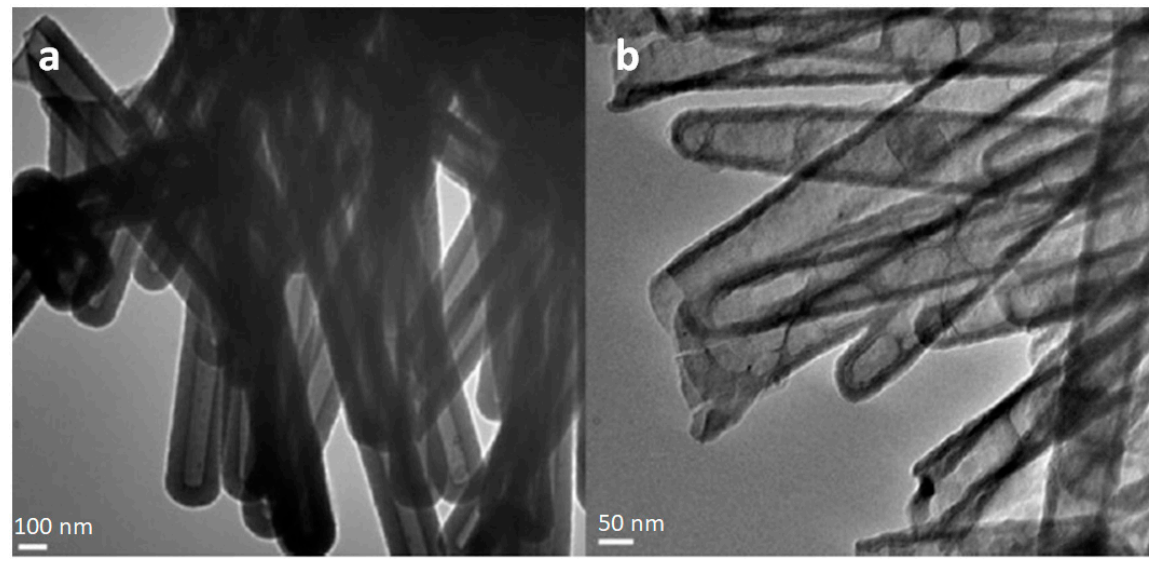

Figure 4. TEM images of SiNTs (a) before $(52.38 \pm 7.04 \mathrm{~nm})$ and (b) after 3-day incubation $(12.63 \pm 2.83 \mathrm{~nm})$ (adapted from [18] with permission).

\section{Nanotube Surface Modification Strategies Relevant to Therapeutic Applications}

The versatile surface chemistry of nanostructured pSi enables attachment of numerous molecules of interest via straightforward coupling chemistry, thereby extending their utility in bio-relevant applications $[17,20]$. With regard to SiNTs, the native oxide surface of as-prepared material allows facile formation of stable siloxane linkages, similar to the case of oxidized pSi surfaces demonstrated previously $[17,21]$. Among possible modifying agents, organoalkoxysilane molecules have been widely used to alter surface properties of the materials via the introduction of a useful functional group at the other end of the organosilane species (amine, thiol, etc.) [22,23]. Much of our emphasis to date has entailed functionalization of SiNTs with amino organosilane (3-aminopropyltriethoxysilane (APTES)) to graft amino terminal groups on the SiNT surface, thereby allowing conjugation with additional 
molecular entities via covalent bonds (polyethylene glycol (PEG) and fluorescent dyes) or electrostatic interactions (polynucleotides). We subsequently discuss the implications of adding these specific moieties for its use as a therapeutic vehicle. Furthermore, we also demonstrate the fact that such amino-terminated SiNTs can be exploited as a synthon for formation of a dispersed scaffold of metallic nanocrystals, such as platinum $(\mathrm{Pt})$, the latter of which exhibit intrinsic anti-cancer activity, thereby expanding the utility of this type of surface-modified nanostructure.

\subsection{PEGylation of SiNTs}

In addition to a lack of toxicity, nanostructures seeking use in a biological context must also remain stable in aqueous solution for long-term storage [24-27]. Depending on solution ionic strength, $\mathrm{pH}$, and physicochemical properties of the nanoparticles, the extent of aggregation will vary [28]. For oxide-terminated nanoparticles, aggregation is often observed due to high surface energy of the materials [29]. One well-studied strategy to prevent particle-particle interaction is shielding the surface with hydrophilic molecules of tunable chain length, such as polyethylene glycol (PEG) [28]. In this case, PEGylation or PEG coating creates a hydrated shell surrounding the nanoparticle core, thereby sterically hindering nanoparticles from interacting with each other [30]. Besides dispersion enhancement, several studies have indicated other benefits of PEGylation, which involve the extension of systematic circulation time and reducing immunogenicity of nanoparticles in vivo [31,32].

This concept was successfully demonstrated using PEG-diacid (600) moieties grafted on amino- terminated SiNT surfaces via 1-ethyl-3-(3-dimethylaminopropyl) carbodiimide (EDC) and N-hydroxysuccinimide (NHS) coupling chemistry [33]. While unmodified SiNTs tend to aggregate within a few hours after sonication, PEGylated SiNTs were not only highly dispersed in deionized $\mathrm{H}_{2} \mathrm{O}$, but also remain suspended in solution for months at room temperature (Figure 5).

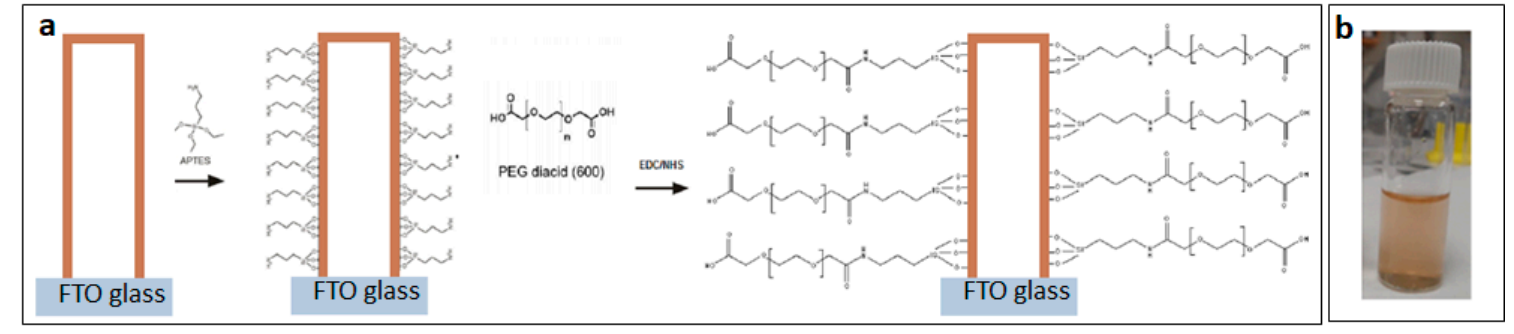

Figure 5. (a) 3-aminopropyltriethoxysilane (APTES) functionalization and PEGylation schemes of SiNTs; (b) Soluble SiNTs (10 nm wall thickness) in deionized water at room temperature after coating with PEG-diacid (600).

\subsection{Fluorescently-Tagged SiNTs}

Fluorescence-based imaging is one of the most important tools in biological studies [34]. In the specific case of gene/drug delivery using nanoparticles, it is crucial to distinguish the drug delivery vehicles from cellular components within the biological microenvironment, thereby determining the fate of the drug carrier [35]. In this regard, simple fluorophore tagging can endow non-fluorescent nanoparticles with an emissive fluorescence feature for bioimaging and related applications [36,37].

In this section, we evaluate the use of SiNTs terminated with THE amino group as a platform for conjugating with two different fluorescent dyes: Fluorescein isothiocyanate (FITC) (green fluorescence, $\lambda_{\mathrm{em}}=520 \mathrm{~nm}$ ) [38] and Alexa Fluor 594 NHS (succinimidyl ester) (red fluorescence, $\lambda_{\mathrm{em}}$ $=615 \mathrm{~nm}$ ) [39]. The amine moeities of APTES molecules conjugated to the SiNT surface react with FITC and Alexa dyes to produce an isothiourea linkage and an amide bond, respectively. In both cases, APTES serves as an efficient linker to stably incorporate fluorescent dyes to the SiNT matrix. Based on confocal fluorescence imaging, SiNT surfaces were successfully labeled with FITC and Alexa dyes, as indicated in uniform emission from the nanotube arrays (Figure 6a,b) [18], therefore implying possible uses of fluorescently-labeled SiNTs in biological studies. To demonstrate this 
concept, Alexa-labeled SiNTs with $35 \mathrm{~nm}$ Si shell thickness were utilized as fluorescent probes to ideally track cellular uptake of SiNTs in HEK 293 cells. By staining the cytoplasm of HEK 293 cells with 3,3'-dioctadecyl-5,5'-di(4-sulfophenyl)oxacarbocyanine, sodium salt (SP-DIOC 18$)(3)$ (green fluorescence, $\lambda_{\mathrm{em}}=513 \mathrm{~nm}$ ), the interaction between Alexa-labeled SiNTs and the cells was clearly observed. Clear accumulation of the labeled SiNTs in the cytoplasm of HEK 293 cells was observed after 24-h exposure (Figure 6), thereby confirming the role of Alexa-labeled SiNTs as an option in cellular labeling [18].
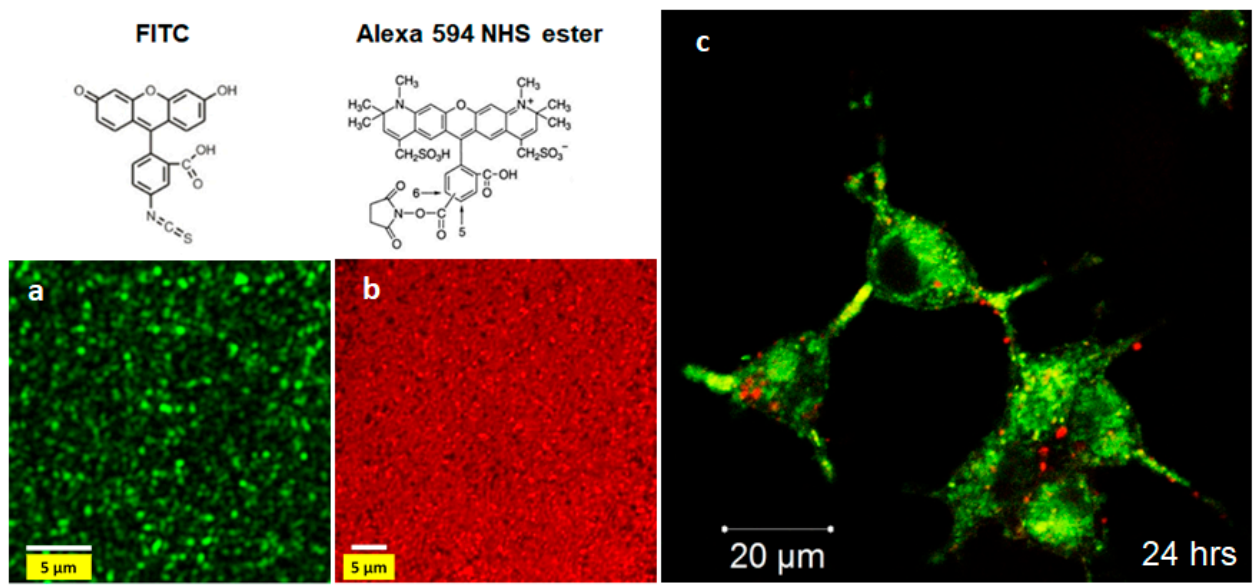

Figure 6. Confocal images of SiNTs after conjugated to (a) fluorescein isothiocyanate (FITC) and (b) Alexa 594 NHS ester using APTES as the coupling agent. (c) Cellular uptake of Alexa-labeled SiNTs (35 nm wall thickness) in human embryonic kidney (HEK) 293 cells (cytoplasm stained SP-DIOC 18 (3)) after $24 \mathrm{~h}$ (adapted from [18] with permission).

\subsection{DNA Immobilization on SiNT Surface through Electrostatic Interaction}

As one of the most exciting new options in the treatment of disease, gene therapy has demonstrated extraordinary potential in the possible treatment of a variety of diseases, such as cancer and heart disease, as well as tissue repair and regeneration [40-42]. This process involves introducing exogenous nucleic acids (e.g., DNA plasmid and small interference RNA) into cellular compartments of the host cells [40]. In order to achieve efficient expression of the foreign genes, fragile genetic materials must be protected from degradation in a biological environment [42].

While selected viruses have been demonstrated as efficient vectors to effectively transfect cells, immunogenicity is a main concern that restricts the application of this route [43,44]. An alternative safer method is using positively charged polymers or cationic lipids to encapsulate negatively charged suitable nucleic acids via electrostatic interactions, thereby forming a stable complex while protecting the cargos from degradation $[45,46]$. Inorganic nanoparticles are yet another appealing option in this regard, owing to their tunable structures, surface chemistry, and compositions [47,48].

Along these lines, we have demonstrated the use of SiNTs as a potential carrier to encapsulate and deliver genetic materials, specifically plasmid DNA (pDNA) encoding green fluorescent protein (GFP) [18]. Initial grafting with APTES ( $\mathrm{pKa}=9.6$ ) converts the negative surface charge of SiNTs to positive owing to the presence of the amino groups, thereby enabling immobilization of pDNA on the SiNT surface [49]. Formation of pDNA/APTES-SiNTs complexes was evaluated by determining the amount of pDNA remaining in the supernatant by an agarose gell electrophoresis assay. Our results indicate complete binding of pDNA to functionalized SiNTs at a 55:1 (pDNA:SiNTs) mass ratio, thereby suggesting potential use of SiNTs as a vector in gene therapy (Figure 7). Evaluation of transfection efficiencies using this system in a suitable in vitro model are underway. 


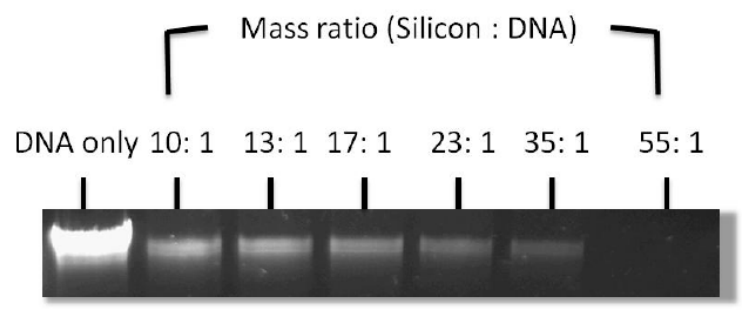

Figure 7. Agarose gel electrophoresis assay showing the unbound plasmid DNA (pDNA) remaining in the solution after incubation with functionalized SiNTs at varying mass ratio (APTES-SiNTs: pDNA). The band intensity reduces as the mass ratio increases, thereby indicating more pDNA bound to the functionalized SiNTs (adapted from [18] with permission).

\subsection{Functionalized SiNTs as a Template for Formation of Platinum Nanocrystals}

Since FDA approval in 1978, the platinum-based drug cisplatin has been effectively utilized to treat a variety of cancers (lymphomas, carcinoma, etc.) [50-52]. However, a lack of specificity and selectivity has led to multiple detrimental side effects, thereby raising legitimate caution in its use as a chemotherapeutic agent [51]. In order to improve the therapeutic efficiency of cisplatin, several drug carrier systems have been developed, such as polymers or inorganic nanoparticles, to effectively deliver a desired payload while avoiding nonspecific delivery to healthy cells [50,53-55].

In terms of possible carrier candidates, SiNTs with ample interior space can ideally load therapeutic molecules, while surface modification of the nanotube carrier allows possible targeting ability for delivery and subsequent release of a useful drug at the disease site(s). One initially envisioned approach involves cisplatin attachment to SiNTs via a linker strategy, in which amino moieties of APTES coordinate to Pt complexes; a locally-concentrated amount of the drug is thereby clustered on SiNTs and, if coupled with a suitably-functionalized targeting peptide (or the alternative) present on the nanotube surface, is ideally delivered to cancer cells.

Interestingly, in initial experiments, instead of observing the intact molecular Pt complexes adsorbed on the SiNT surface, we detected a highly dense cluster of crystalline platinum species (1-3 nm) uniformly deposited on SiNTs (Figure 8a). By evaluating possible impurities in the cisplatin using standard spectrometric assays of the $\lambda_{310} / \lambda_{247}$ ratio [56], we discovered the presence of significant amounts of $\mathrm{K}_{2} \mathrm{PtCl}_{4}$, (common precursor in cisplatin synthesis) and that this species was responsible for the formation of elemental Pt on functionalized SiNTs [57]. As Pt nanocrystals (Pt NCs) preferentially form on functionalized SiNTs, but not on as-prepared unmodified SiNTs, it is clear that the presence of the primary amine moieties of APTES coordinate with $\mathrm{PtCl}_{4}{ }^{2-}$ and play a role in the reduction of $\mathrm{Pt}^{2+}$ to $\mathrm{Pt}^{0}$.[58]

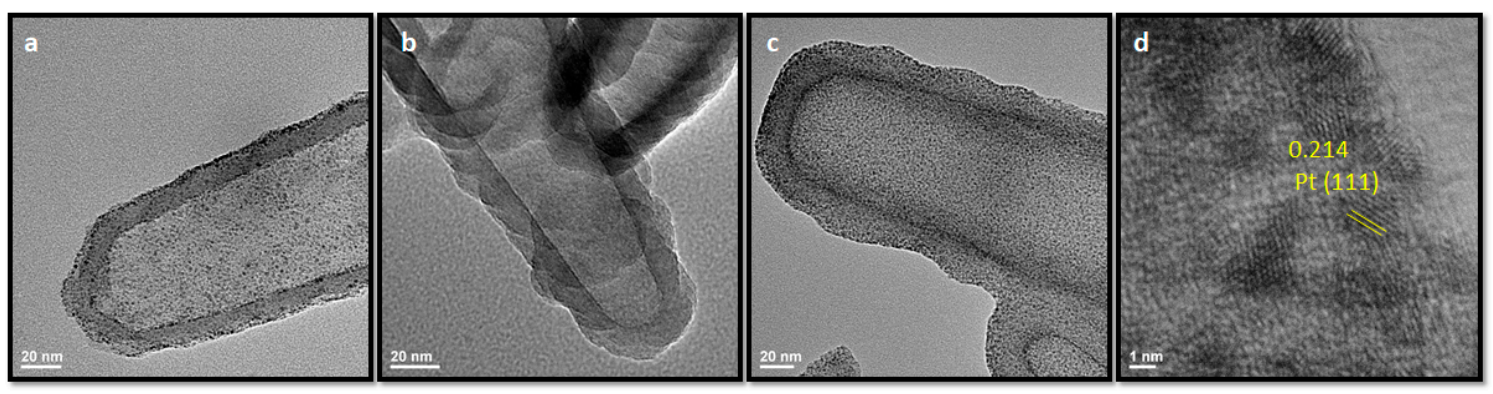

Figure 8. TEM images of SiNTs after incubated in (a) impure cisplatin ( $15 \mathrm{wt} \%$ platinum (Pt), evaluated by erergy dispersive x-ray analysis (EDX), (b) pure cisplatin (>95\%) ( 2 wt \% Pt, EDX), (c) $\mathrm{K}_{2} \mathrm{PtCl}_{4}(50 \mathrm{wt} \% \mathrm{Pt}, \mathrm{EDX})$. (d) High resolution TEM image showing lattice spacing of $\mathrm{Pt}$ species deposited on SiNTs after using $\mathrm{K}_{2} \mathrm{PtCl}_{4}$ as a Pt precursor.

Although this result is unexpected in terms of cisplatin loading, we have discovered a new synthetic route to readily synthesize ultra-small Pt NCs on the SiNT matrix using $\mathrm{K}_{2} \mathrm{PtCl}_{4}$ as a Pt 
precursor. While Pt-based drugs (e.g., cisplatin, carboplatin) have been exploited in cancer treatment, noticeably, reports in recent years have demonstrated Pt NCs (1-3 nm) as an alternative anticancer reagent which can effectively overcome chemoresistance in some cancer cell lines, such as hepatocellular carcinoma (HCC) [59-61]. Inspired by these preceding studies, investigations in Pt NCs deposition on SiNTs using $\mathrm{K}_{2} \mathrm{PtCl}_{4}$ and in vitro toxicity of the Pt NCs-SiNT composites are ongoing in our lab to evaluate the associated therapeutic activity of this novel material.

\section{Loading of the Nanotube Interior}

From a geometric perspective, the rather large and tunable inner cavity of a SiNT presents a significant loading opportunity for applications involving delivery of a therapeutic cargo. In a rather novel twist to this strategy, we have actually demonstrated the efficient loading of biocompatible superparamagnetic iron oxide nanoparticles into the interior of different SiNT inner diameters (Figure 9) [62,63].

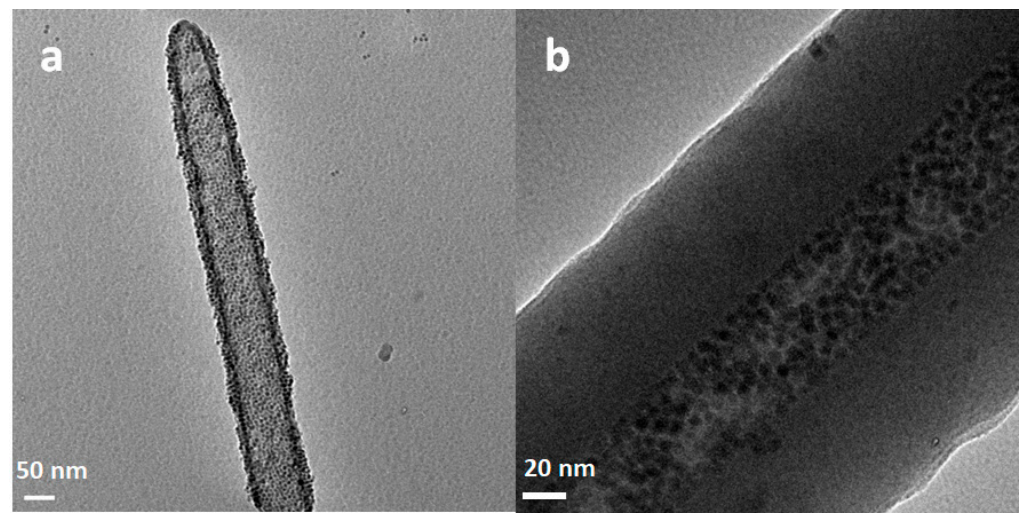

Figure 9. TEM images of (a) $4 \mathrm{~nm} \mathrm{Fe}_{3} \mathrm{O}_{4}$ nanocrystals loaded into $10 \mathrm{~nm}$ shell SiNTs; (b) 4 nm $\mathrm{Fe}_{3} \mathrm{O}_{4}$ nanocrystals loaded in $70 \mathrm{~nm}$ thick SiNTs.

Using this strategy, one can ideally achieve targeted delivery of a drug attached to the outer nanotube surface, while guided by the presence of an external magnetic field to the desired site in vitro/in vivo [64]. This is in contrast to the alternative strategy of functionalizing the outer nanotube surface with a targeting moiety (e.g., antibody or peptide) and subsequently loading the nanotube interior with a desired therapeutic species.

\section{Conclusion}

This review has covered a number of key aspects of SiNTs that have interesting implications in therapeutics. While additional opportunities remain, multiple clear advantages of exploiting surface tunability of SiNTs for exploiting their functional tubular structure have been demonstrated. Studies involving biocompatibility of the SiNTs and applications in drug/gene delivery are underway to broaden our knowledge of its interactions with biological systems and potential applications of this novel one-dimensional material.

Author Contributions: N.T.L. and J.L.C. conceived the initial outline for this manuscript; N.T.L. wrote the first draft, subsequently refined by N.T.L. and J.L.C.; Y.T. performed SiNT dissolution experiments in complete medium, in vitro experiments with labeled NTs, and DNA binding experiments; R.G.-R. performed initial SiNT dissolution experiments in water and PBS, PEGylation experiments, and superparamagnetic loading experiments; N.T.L. acquired the SiNT TEM characterization results shown, as well as performing all SiNT/Pt nanocrystal experiments.

Funding: The authors wish to thank the Robert A. Welch Foundation, Grant P-1212 (to JLC) for financial support of this research.

Conflicts of Interest: The authors declare no conflict of interest. 


\section{References}

1. Canham, L.T. Bioactive silicon structure fabrication through nanoetching techniques. Adv. Mater. 1995, 7, 1033-1037. [CrossRef]

2. Anglin, E.J.; Cheng, L.; Freeman, W.R.; Sailor, M.J. Porous silicon in drug delivery devices and materials. Adv. Drug Deliv. Rev. 2008, 60, 1266-1277. [CrossRef] [PubMed]

3. Low, S.P.; Voelcker, N.H. Biocompatibility of Porous Silicon. In Handbook of Porous Silicon; Canham, L., Ed.; Springer International Publishing: Cham, Switzerland, 2018; pp. 533-545. [CrossRef]

4. Starkov, V.V.; Gosteva, E.A.; Sedlovets, D.M.; Kah, M.O. Silicon Structures with Variable Morphology of Pores Methods of Obtaining Physical and Optical Properties. J. Electrochem. Soc. 2018, 165, E534-E539. [CrossRef]

5. Canham, L. Tunable Properties of Porous Silicon. In Handbook of Porous Silicon; Canham, L., Ed.; Springer International Publishing: Cham, Switzerland, 2018; pp. 283-290. [CrossRef]

6. Li, W.; Liu, Z.; Fontana, F.; Ding, Y.; Liu, D.; Hirvonen, J.T.; Santos, H.A. Tailoring Porous Silicon for Biomedical Applications: From Drug Delivery to Cancer Immunotherapy. Adv. Mater. 2018, 30, 1703740. [CrossRef]

7. Salonen, J.; Kaukonen, A.M.; Hirvonen, J.; Lehto, V.-P. Mesoporous silicon in drug delivery applications. J. Pharm. Sci. 2008, 97, 632-653. [CrossRef]

8. Shtenberg, G.; Segal, E. Porous Silicon Optical Biosensors. In Handbook of Porous Silicon; Canham, L., Ed.; Springer International Publishing: Cham, Switzerland, 2014; pp. 857-868. [CrossRef]

9. Fagan, S.B.; Baierle, R.J.; Mota, R.; da Silva, A.J.R.; Fazzio, A. Ab initio calculations for a hypothetical material: Silicon nanotubes. Phys. Rev. B 2000, 61, 9994-9996. [CrossRef]

10. Coffer, J. Mesoporous nanotubes as biomaterials. Mesoporous Biomater. 2016, 2. [CrossRef]

11. Huang, X.; Gonzalez-Rodriguez, R.; Rich, R.; Gryczynski, Z.; Coffer, J.L. Fabrication and size dependent properties of porous silicon nanotube arrays. Chem. Commun. 2013, 49, 5760-5762. [CrossRef]

12. Tesfaye, A.T.; Gonzalez, R.; Coffer, J.L.; Djenizian, T. Porous Silicon Nanotube Arrays as Anode Material for Li-Ion Batteries. ACS Appl. Mater. Interfaces 2015, 7, 20495-20498. [CrossRef]

13. Gonzalez-Rodriguez, R.; Arad-Vosk, N.; Rozenfeld, N.; Sa'ar, A.; Coffer, J.L. Control of CH3NH3PbI3 Perovskite Nanostructure Formation through the Use of Silicon Nanotube Templates. Small 2016, 12, 4477-4480. [CrossRef]

14. Arad-Vosk, N.; Rozenfeld, N.; Gonzalez-Rodriguez, R.; Coffer, J.L.; Sa'ar, A. Inhibition of a structural phase transition in one-dimensional organometal halide perovskite nanorods grown inside porous silicon nanotube templates. Phys. Rev. B 2017, 95, 085433. [CrossRef]

15. Shabir, Q. Biodegradability of Porous Silicon. In Handbook of Porous Silicon; Canham, L., Ed.; Springer International Publishing: Cham, Switzerland, 2014; pp. 395-401. [CrossRef]

16. Le, N.T.; Coffer, J.L. Silicon Nanomaterials Sourcebook; Sattler, K.D., Ed.; CRC Press: Boca Raton, FL, USA, 2017. [CrossRef]

17. Sailor, M.J. Porous Silicon in Practice: Preparation, Characterization and Applications; Wiley-VCH: Weinheim, Germany, 2012.

18. Tian, Y. Silicon- and Germanium-Based Nanomaterial Cytocompatibility and Gene Delivery; Texas Christian University: Fort Worth, TX, USA, 2014.

19. Rodriguez, R.G. Silicon Nanotubes and Selected Investigations in Energy and Biomaterial Applications; Texas Christian University: Fort Worth, TX, USA, 2017.

20. Nijdam, A.J.; Ming-Cheng, M.; Geho, D.H.; Fedele, R.; Herrmann, P.; Killian, K.; Espina, V.; Petricoin, E.F.; Liotta, L.A.; Ferrari, M. Physicochemically modified silicon as a substrate for protein microarrays. Biomaterials 2007, 28, 550-558. [CrossRef] [PubMed]

21. Majoul, N.; Aouida, S.; Bessaïs, B. Progress of porous silicon APTES-functionalization by FTIR investigations. Appl. Surf. Sci. 2015, 331, 388-391. [CrossRef]

22. Lee, H.S.; Kang, S.J.; Kim, D. A Mini Review: Recent Advances in Surface Modification of Porous Silicon. Materials 2018, 11, 2557. [CrossRef] [PubMed]

23. De Stefano, L.; Oliviero, G.; Amato, J.; Borbone, N.; Piccialli, G.; Mayol, L.; Rendina, I.; Terracciano, M.; Rea, I. Aminosilane functionalizations of mesoporous oxidized silicon for oligonucleotide synthesis and detection. J. R. Soc. Interface 2013, 10, 20130160. [CrossRef] 
24. Cardellini, A.; Alberghini, M.; Govind Rajan, A.; Misra, R.P.; Blankschtein, D.; Asinari, P. Multi-scale approach for modeling stability, aggregation, and network formation of nanoparticles suspended in aqueous solutions. Nanoscale 2019, 11, 3979-3992. [CrossRef]

25. Lee, S.B. Nanotoxicology: Toxicity and biological effects of nanoparticles for new evaluation standards. Nanomedicine 2011, 6, 759-761. [CrossRef]

26. Lazzari, S.; Moscatelli, D.; Codari, F.; Salmona, M.; Morbidelli, M.; Diomede, L. Colloidal stability of polymeric nanoparticles in biological fluids. J. Nanoparticle Res. 2012, 14, 920. [CrossRef]

27. Izak-Nau, E.; Huk, A.; Reidy, B.; Uggerud, H.; Vadset, M.; Eiden, S.; Voetz, M.; Himly, M.; Duschl, A.; Dusinska, M.; et al. Impact of storage conditions and storage time on silver nanoparticles' physicochemical properties and implications for their biological effects. Rsc. Adv. 2015, 5, 84172-84185. [CrossRef]

28. Guerrini, L.; Alvarez-Puebla, A.R.; Pazos-Perez, N. Surface Modifications of Nanoparticles for Stability in Biological Fluids. Materials 2018, 11, 1154. [CrossRef]

29. Wu, W.; He, Q.; Jiang, C. Magnetic iron oxide nanoparticles: Synthesis and surface functionalization strategies. Nanoscale Res. Lett. 2008, 3, 397-415. [CrossRef] [PubMed]

30. Daley, K.R.; Kubarych, K.J. An “Iceberg” Coating Preserves Bulk Hydration Dynamics in Aqueous PEG Solutions. J. Phys. Chem. B 2017, 121, 10574-10582. [CrossRef] [PubMed]

31. Gabizon, A.; Catane, R.; Uziely, B.; Kaufman, B.; Safra, T.; Cohen, R.; Martin, F.; Huang, A.; Barenholz, Y. Prolonged Circulation Time and Enhanced Accumulation in Malignant Exudates of Doxorubicin Encapsulated in Polyethylene-glycol Coated Liposomes. Cancer Res. 1994, 54, 987. [PubMed]

32. Jokerst, J.V.; Lobovkina, T.; Zare, R.N.; Gambhir, S.S. Nanoparticle PEGylation for imaging and therapy. Nanomedicine 2011, 6, 715-728. [CrossRef]

33. Gonzalez-Rodriguez, R.; Granitzer, P.; Rumpf, K.; Coffer, J.L. New MRI contrast agents based on silicon nanotubes loaded with superparamagnetic iron oxide nanoparticles. R. Soc. Open Sci. 2018, 5, 180697. [CrossRef]

34. Specht, E.A.; Braselmann, E.; Palmer, A.E. A Critical and Comparative Review of Fluorescent Tools for Live-Cell Imaging. Annu. Rev. Physiol. 2017, 79, 93-117. [CrossRef]

35. Shang, L.; Nienhaus, G.U. Small fluorescent nanoparticles at the nano-bio interface. Mater. Today 2013, 16, 58-66. [CrossRef]

36. Natte, K.; Behnke, T.; Orts-Gil, G.; Würth, C.; Friedrich, J.F.; Österle, W.; Resch-Genger, U. Synthesis and characterisation of highly fluorescent core-shell nanoparticles based on Alexa dyes. J. Nanoparticle Res. 2012, 14, 680. [CrossRef]

37. Wang, W.; Nallathamby, P.D.; Foster, C.M.; Morrell-Falvey, J.L.; Mortensen, N.P.; Doktycz, M.J.; Gu, B.; Retterer, S.T. Volume labeling with Alexa Fluor dyes and surface functionalization of highly sensitive fluorescent silica $\left(\mathrm{SiO}_{2}\right)$ nanoparticles. Nanoscale 2013, 5, 10369-10375. [CrossRef]

38. Hermanson, G.T. Chapter 10—Fluorescent Probes. In Bioconjugate Techniques (Third Edition); Hermanson, G.T., Ed.; Academic Press: Boston, MA, USA, 2013; pp. 395-463. [CrossRef]

39. Whitson, K.B.; Beechem, J.M.; Beth, A.H.; Staros, J.V. Preparation and characterization of Alexa Fluor 594-labeled epidermal growth factor for fluorescence resonance energy transfer studies: Application to the epidermal growth factor receptor. Anal. Biochem. 2004, 324, 227-236. [CrossRef]

40. Lostalé-Seijo, I.; Montenegro, J. Synthetic materials at the forefront of gene delivery. Nat. Rev. Chem. 2018, 2, 258-277. [CrossRef]

41. Wu, P.; Chen, H.; Jin, R.; Weng, T.; Ho, J.K.; You, C.; Zhang, L.; Wang, X.; Han, C. Non-viral gene delivery systems for tissue repair and regeneration. J. Transl. Med. 2018, 16, 29. [CrossRef] [PubMed]

42. Matkar, P.N.; Leong-Poi, H.; Singh, K.K. Cardiac gene therapy: Are we there yet? Gene Ther. 2016, $23,635$. [CrossRef] [PubMed]

43. Wang, D.; Tai, P.W.L.; Gao, G. Adeno-associated virus vector as a platform for gene therapy delivery. Nat. Rev. Drug Discov. 2019, 18, 358-378. [CrossRef]

44. Nayak, S.; Herzog, R.W. Progress and prospects: Immune responses to viral vectors. Gene Ther. 2009, 17, 295. [CrossRef]

45. Van Bruggen, C.; Hexum, J.K.; Tan, Z.; Dalal, R.J.; Reineke, T.M. Nonviral Gene Delivery with Cationic Glycopolymers. Acc. Chem. Res. 2019, 52, 1347-1358. [CrossRef]

46. Yin, H.; Kanasty, R.L.; Eltoukhy, A.A.; Vegas, A.J.; Dorkin, J.R.; Anderson, D.G. Non-viral vectors for gene-based therapy. Nat. Rev. Genet. 2014, 15, 541-555. [CrossRef] 
47. Loh, X.J.; Lee, T.-C.; Dou, Q.; Deen, G.R. Utilising inorganic nanocarriers for gene delivery. Biomater. Sci. 2016, 4, 70-86. [CrossRef]

48. Riley, K.M.; Vermerris, W. Recent Advances in Nanomaterials for Gene Delivery-A Review. Nanomaterials 2017, 7, 94. [CrossRef]

49. Pick, C.; Argento, C.; Drazer, G.; Frechette, J. Micropatterned Charge Heterogeneities via Vapor Deposition of Aminosilanes. Langmuir 2015, 31, 10725-10733. [CrossRef]

50. Ma, P.a.; Xiao, H.; Li, C.; Dai, Y.; Cheng, Z.; Hou, Z.; Lin, J. Inorganic nanocarriers for platinum drug delivery. Mater. Today 2015, 18, 554-564. [CrossRef]

51. Tsang, R.Y.; Al-Fayea, T.; Au, H.-J. Cisplatin Overdose. Drug Saf. 2009, 32, 1109-1122. [CrossRef] [PubMed]

52. Kelland, L. The resurgence of platinum-based cancer chemotherapy. Nat. Rev. Cancer 2007, 7, 573. [CrossRef] [PubMed]

53. Khiati, S.; Luvino, D.; Oumzil, K.; Chauffert, B.; Camplo, M.; Barthélémy, P. Nucleoside-Lipid-Based Nanoparticles for Cisplatin Delivery. ACS Nano 2011, 5, 8649-8655. [CrossRef] [PubMed]

54. Mochida, Y.; Cabral, H.; Miura, Y.; Albertini, F.; Fukushima, S.; Osada, K.; Nishiyama, N.; Kataoka, K. Bundled Assembly of Helical Nanostructures in Polymeric Micelles Loaded with Platinum Drugs Enhancing Therapeutic Efficiency against Pancreatic Tumor. ACS Nano 2014, 8, 6724-6738. [CrossRef]

55. Mandriota, G.; Di Corato, R.; Benedetti, M.; De Castro, F.; Fanizzi, F.P.; Rinaldi, R. Design and Application of Cisplatin-Loaded Magnetic Nanoparticle Clusters for Smart Chemotherapy. ACS Appl. Mater. Interfaces 2019, 11, 1864-1875. [CrossRef]

56. Reishus, J.W.; Martin, D.S. cis-Dichlorodiammineplatinum(II). Acid Hydrolysis and Isotopic Exchange of the Chloride Ligands1. J. Am. Chem. Soc. 1961, 83, 2457-2462. [CrossRef]

57. Dhara, S. A rapid method for the synthesis of cis- $\left[\mathrm{Pt}\left(\mathrm{NH}_{3}\right)_{2} \mathrm{Cl}_{2}\right]$. Indian J. Chem. 1970, 8, $193-194$.

58. Le, N.T.; Coffer, J.L. Formation of Platinum Nanocrystals on Porous Silicon Nanotubes. In Proceedings of the Porous Semiconductors-Science and Technology Conference 2018, La Grande Motte, France, 11-16 March 2018

59. Chien, C.-T.; Yan, J.-Y.; Chiu, W.-C.; Wu, T.-H.; Liu, C.-Y.; Lin, S.-Y. Caged Pt Nanoclusters Exhibiting Corrodibility to Exert Tumor-Inside Activation for Anticancer Chemotherapeutics. Adv. Mater. 2013, 25, 5067-5073. [CrossRef]

60. Xia, H.; Li, F.; Hu, X.; Park, W.; Wang, S.; Jang, Y.; Du, Y.; Baik, S.; Cho, S.; Kang, T.; et al. pH-Sensitive Pt Nanocluster Assembly Overcomes Cisplatin Resistance and Heterogeneous Stemness of Hepatocellular Carcinoma. ACS Cent. Sci. 2016, 2, 802-811. [CrossRef]

61. Shoshan, M.S.; Vonderach, T.; Hattendorf, B.; Wennemers, H. Peptide-Coated Platinum Nanoparticles with Selective Toxicity against Liver Cancer Cells. Angew. Chem. Int. Ed. 2019, 58, 4901-4905. [CrossRef] [PubMed]

62. Granitzer, P.; Rumpf, K.; Gonzalez, R.; Coffer, J.; Reissner, M. Magnetic properties of superparamagnetic nanoparticles loaded into silicon nanotubes. Nanoscale Res. Lett. 2014, 9, 413. [CrossRef] [PubMed]

63. Granitzer, P.; Rumpf, K.; Gonzalez-Rodriguez, R.; Coffer, J.L.; Reissner, M. The effect of nanocrystalline silicon host on magnetic properties of encapsulated iron oxide nanoparticles. Nanoscale 2015, 7, 20220-20226. [CrossRef] [PubMed]

64. Gonzalez-Rodriguez, R. 10 nm Magnetite Nanoparticles Inside Si NTs. Available online: https://www. youtube.com/watch?v=1xDFAQSS2T0 (accessed on 1 September 2019).

(C) 2019 by the authors. Licensee MDPI, Basel, Switzerland. This article is an open access article distributed under the terms and conditions of the Creative Commons Attribution (CC BY) license (http://creativecommons.org/licenses/by/4.0/). 